ganglia. In Rett syndrome, the neurons may be genetically defective.

The differentiation of infantile autism and Rett syndrome may be difficult in infancy. The head size can be an important diagnostic indicator. Macrocephaly in children and adults with autism is reported from the University of Utah Neuropsychiatric Institute, Salt Lake City, UT. (Lainhart JE, Piven J, Wzorek M, et al. I Am Acad Child Adolesc Psychiatry Feb 1997;36:282290). In $14 \%$ of 91 subjects with autism, the head circumference was above the 97 th percentile at a mean age of 14 years (range, 3 to 38 years), even when corrected for height; macrocephaly was usually not present at birth. Accelerated head growth occurs after 4 years of age in $37 \%$ of children with autism. MRI studies were mostly normal.

\title{
ANGELMAN SYNDROME: MOLECULAR CYTOGENETIC STUDIES
}

Clinical, neurological, and molecular genetic studies of 22 patients with diagnostic features of Angelman syndrome (AS) are reported from National Taiwan University Hospital, Taipei. A deletion of region 15q11-13 was identified cytogenetically in 11 cases by high-resolution technique. Four cases were confirmed by fluorescence in situ hybridization (FISH). The remaining 7 cases had no deletions over 15q11-13. Clinical features of AS were obvious after 2 years of age. During infancy AS may be mistaken for Rett syndrome, ataxic cerebral palsy, Prader-Willi syndrome, or infantile autism. (Hou J-W, Wang PJ, Wang T-R. Angelman syndrome assessed by neurological and molecular cytogenetic investigations. Pediatr Neurol Jan 1997;16:17-22). (Respond: Dr Hou, Department of Pediatrics, National Taiwan University Hospital, 7 Chung-Shan South Rd, Taipei 10016, Taiwan).

COMMENT. Seizures occur in $80 \%$ of cases of Angelman syndrome, usually by 2 years of age, and Boyd and colleagues, Great Ormond Street Hospital, London, have described characteristic EEG findings that are included among diagnostic criteria for AS. In the above report, EEG findings were sometimes absent at an early age, and cytogenetic confirmation of the diagnosis was stressed.

\section{MENKES' SYNDROME WITH CEREBELLAR HYPOPLASIA}

A 14-month-old boy with Menkes' kinky hair syndrome (MS) associated with deafness and inferior cerebellar vermian hypoplasia was admitted with convulsions and urinary infection at Karadeniz Technical University, Trabzon, Turkey. Physical findings included microcephaly, growth and weight < 3rd percentile, developmental retardation, coarse wiry hair (pili torti), optic atrophy, and spastic diplegia. MRI showed subdural effusion, cerebral atrophy, and inferior vermian hypoplasia. Cystography revealed bladder diverticulae. Serum copper was $69 \mathrm{~g} / \mathrm{dl}$ and ceruloplasmin $4.45 \mathrm{mg} / \mathrm{dl}$. (Aynaci FM, Mocan H, Bahadir S, et al. A case of Menkes' syndrome associated with deafness and inferior cerebellar vermian hypoplasia. Acta Paediatr Jan 1997;86:121-123). (Respond: Dr FM Aynaci, Dept of Paediatrics, Faculty of Medicine, Karadeniz Technical University, Trabzon/Turkey).

COMMENT. Several variants of Menkes' syndrome have been recognized, including an ataxic presentation (Menkes JH. Textbook of Child Neurology, Philadelphia, Lea \& Febiger). This appears to be the first documentation of a case with cerebellar hypolasia. The syndrome is an X-linked recessive disorder, and the gene has been assigned to Xq 13. 